\title{
ESTADO DE BIENESTAR, FELICIDAD Y PRODUCCIÓN EN LA UE.
}

\section{WELFARE STATE, HAPPINESS AND PRODUCTION IN THE EU.}

Ortega Gil, Manuela (Universidad de Cádiz) *

Cortés Sierra, Georgina (Universidad de Extremadura) ${ }^{* *}$

\section{RESUMEN}

El Estado de Bienestar se concibe como un modelo político cuyo objeto principal es facilitar la igualdad de oportunidades y garantizar las necesidades básicas de los que tienen rentas menores por medio de políticas sociales. Existen posturas opuestas sobre su utilidad, necesidad, eficacia y eficiencia económica porque requiere de un volumen considerable de recursos financieros, principalmente aportados por los trabajadores y las empresas mediante impuestos en función de sus rentas. Por un lado, se encuentran aquellos que sostienen que la intervención del Estado se ha de reducir al mínimo para no perjudicar a la actividad económica y a la creación de empleo. Por otro lado, se hallan los que apoyan la existencia del Estado de Bienestar porque aumenta la productividad de la economía mediante las mejoras del capital humano y del capital social. Este trabajo analiza mediante técnicas estadísticas y econométricas las políticas sociales, la felicidad y la productividad para valorar el retorno del gasto público a los ciudadanos por dos vías, la individual (bienestar subjetivo) y la económica (producción per cápita) de los países de la UE en el año 2014.

Palabras claves: Estado de Bienestar, felicidad, productividad, utilidad. JEL: D6, H0, I3.

\section{ABSTRACT}

The welfare state is envisaged as a political model whose main objective is to ensure equality of opportunity and to guarantee basic needs of those on low incomes through social policies.

There are opposing positions about the economic utility, necessity, effectiveness and efficiency because this model would require a considerable demand of financial resources, mainly contributed by workers and companies through the different taxes paid according to their income. On the one hand, those who argue that it should be reduce government intervention until minimum as not to harm the economic activity and creating jobs. On the other hand, there are those who support the existence of the welfare state because it increases the productivity of the economy with the best human capital and social capital. This paper analyses social policies, happiness and productivity to assess the return of public spending to citizens in two ways: individual (subjective well-being) and economic (per capita production) of the countries of the EU in the year 2014.

Key words: Welfare State, happiness, productivity, utility. JEL: D6, H0, I3.

* Departamento de Economía General, Área de Economía Aplicada, Facultad de Ciencias Económicas y Empresariales (Sede Algeciras), Edificio I+D+I Campus Tecnológico, Despacho 2.09, Cádiz. manuela.ortega@uca.es

** Departamento de Economía, Área Métodos cuantitativos para la economía y la empresa, Facultad de Ciencias Económicas y Empresariales, Avda. de Elvas, 06071, Badajoz.georgina@unex.es

Recibido: Diciembre de 2016. Aceptado: Febrero de 2017. 


\section{INTRODUCCIÓN}

Las funciones del Estado de Bienestar y su influencia sobre la redistribución de la renta y la calidad de vida de la población se encuentran en el centro de los debates académicos y políticos. En la actualidad se consideran cuatro modelos de Estado de Bienestar; el liberal anglosajón, el conservador, el socialdemócrata o nórdico y el mediterráneo (Esping, 1990). En función de estos modelos se definen su naturaleza y funciones, de este modo algunos expertos señalan el pleno empleo y la protección social como objetivos principales; mientras que otros afirman que el Estado de Bienestar es mucho más, que es el conjunto de intervenciones de los gobiernos con finalidades sociales y redistributivas que mejoran el bienestar y la calidad de vida de la población. El impacto de un Estado de Bienestar fuerte sobre la equidad en la distribución de las rentas contribuye a mejorar las oportunidades, la cohesión social de los ciudadanos y, por consiguiente, su calidad de vida, que está directamente relacionada con la felicidad mediante el grado de satisfacción con la vida (Cabrero, 2004). Otro punto crucial en las discusiones sobre el Estado de Bienestar es el de la eficiencia de las políticas sociales para la economía y la población de un país.

En la Unión Europea (UE), el interés de los estudios sobre el Estado de Bienestar se ha centrado en su naturaleza y funcionalidad, en el impacto sobre la calidad de vida, la eficiencia y la eficacia de las políticas sociales. Desde la perspectiva económica, las políticas neoliberales proponen la reducción del gasto social junto a la liberalización de los mercados $\mathrm{y}$, por consiguiente, la privatización de servicios como la educación y la sanidad, las reducciones de impuestos y los recortes de otros gastos sociales como prestaciones y pensiones. Estas medidas se justifican en razón a una mayor eficacia, eficiencia y competitividad del sector privado frente al sector público "el discurso que defienden estas políticas se sustenta en que los programas sociales son un despilfarro innecesario para ayudar a personas que se vuelven acomodaticias y perezosas” (Rodríguez, 2014:18-19).

Por otro lado, el modelo keynesiano apuesta por la utilización del gasto social como motor de la economía en épocas de crisis, aumentando la demanda y produciendo en el corto plazo mayor impacto sobre la producción real y el empleo que sobre la inflación. Existen otros autores cuya opinión es que el gasto social solo es rentable si contribuye a la creación de infraestructura económica y social; en consecuencia, las políticas sociales se han de orientar más a cómo se gasta que a la cantidad gastada (Hernández, 2010).

Desde la perspectiva de los ciudadanos, cabe plantearse si estos serán más felices con políticas que desarrollan el Estado de Bienestar y requieren recaudar impuestos más altos, o con un modelo fundamentado en la privatización donde el peso del sector público sea muy bajo y los impuestos para su sostenimiento también lo sean.

Este trabajo es un análisis del Estado de Bienestar, la felicidad y la producción en los países de la Unión Europea durante el año 2014 y pretende estudiar y analizar:

1. La distribución y composición del gasto social de los Estados de Bienestar.

2. Las divisiones o tipos del gasto social como garantes de la felicidad.

3. El tipo de gasto social que afecta más a la felicidad.

4. Las relaciones entre los tipos de gasto social y la producción per cápita.

5. La asociación entre la felicidad, el tipo de gasto social y la producción de estos países.

Para ello, se parte de las siguientes hipótesis:

1. Los ciudadanos de países con mayor gasto social per cápita son más felices.

2. Un país con ciudadanos más felices es más productivo. 
3. Un país con mayor gasto social per cápita es más productivo.

4. Un país con sus ciudadanos más felices y con mayor gasto social per cápita es más productivo.

Sobre estas cuestiones existen estudios que muestran cómo la felicidad de los trabajadores (satisfacción laboral) es un factor de la productividad. Angulo, Quejada y Yánez (2012) la consideran como parte de la realidad subjetiva del mercado laboral. Asimismo, Dutschke (2013) pone de manifiesto la importancia del reconocimiento, de la posibilidad de desarrollo personal y profesional y del ambiente interno de la empresa para la producción y la felicidad laboral.

\section{POLÍTICA SOCIAL Y ESTADO DE BIENESTAR}

La política social y el Estado de Bienestar están muy entrelazados. Según (Navarro, 2004) el Estado de Bienestar se compone de las intervenciones del Estado a escala central, autonómica o local, con la finalidad de mejorar el bienestar social y la calidad de vida de la población. Entre estas se encuentran:

a) Los servicios públicos (sanidad, educación y las ayudas sociales).

b) Las transferencias sociales (pensión, viudedad, discapacidad). Algunas son contributivas y otras no contributivas.

c) Las intervenciones normativas (aquellas destinadas a la protección de la población en materia de salud e higiene laboral, protección al consumidor y salud ambiental). Estas normalmente no necesitan de financiación, sino que se basan en normas y sanciones que obligan a su cumplimiento.

d) Las intervenciones públicas para la creación de empleo, concretamente, las Políticas Activas de Empleo.

Consecuentemente, el estudio del Estado de Bienestar se ocupa tanto del gasto/inversión social como de la normativa existente en materia social. El gasto/inversión social es un instrumento de redistribución de la renta $\mathrm{y}$, por tanto, de acuerdo con las políticas keynesianas, un potenciador de la demanda, de la producción y de la creación de empleo.

Sin embargo, en la última crisis, que se ha caracterizado por provocar altas tasas de desempleo, la UE adoptó políticas neoliberales con importantes recortes sociales; a diferencia de EEUU que utilizó políticas keynesianas. La UE dirigió sus políticas, principalmente, a la contención del gasto público y al control del déficit público obligando a los países a aplicar políticas contractivas (políticas de austeridad) que provocaron un aumento del desempleo junto a una disminución de la producción y la demanda.

El artículo 3 del Tratado de la Unión Europea (TUE), destaca la importancia de las políticas sociales y de empleo para la Unión. Sin embargo, la UE decidió, a pesar de no ser prioritario en la Estrategia Europea 2020 (Fresno, Renes y Tsolakis, 2012), controlar el déficit público por encima de la creación de empleo. Sus políticas desde 2008 no solo se centran en los recortes sociales, sino que también tienen como fin cambiar las normativas para flexibilizar los mercados, reducir las estructuras gubernamentales, eliminar prestaciones sociales y privatizar la sanidad, la educación e, incluso, la defensa y la seguridad (González, 2011).

La crisis, junto a las políticas adoptadas han conducido a un aumento de la desigualdad y la pobreza en Europa, siendo estos efectos mayores en España. Así, según los datos de 
Eurostat (2016), en 2014 la tasa de riesgo de pobreza ${ }^{1}$ después de transferencias sociales era del 17.2 por 100 en la UE frente al 22.2 por 100 en España. A pesar de estos datos el gasto público y el de protección social en porcentaje del PIB en España fueron inferiores (43.6 y 39.7 por 100$)$ al de la UE (48.1 y 40.2 por 100 ) respectivamente.

Esto resulta particularmente grave puesto que las transferencias sociales contribuyen a reducir la población en riesgo de pobreza como se puede constatar en el gráfico 1, en mayor medida en los países con menor grado de Estado de Bienestar, como el caso de Bulgaria que su introducción reduce en un 19.3 por 100 el porcentaje de población en riesgo de pobreza.

\section{GRÁFICO 1. PORCENTAJE DE POBLACIÓN EN RIESGO DE POBREZA ANTES Y DESPUÉS DE LAS TRANSFERENCIAS SOCIALES, UE 2014.}

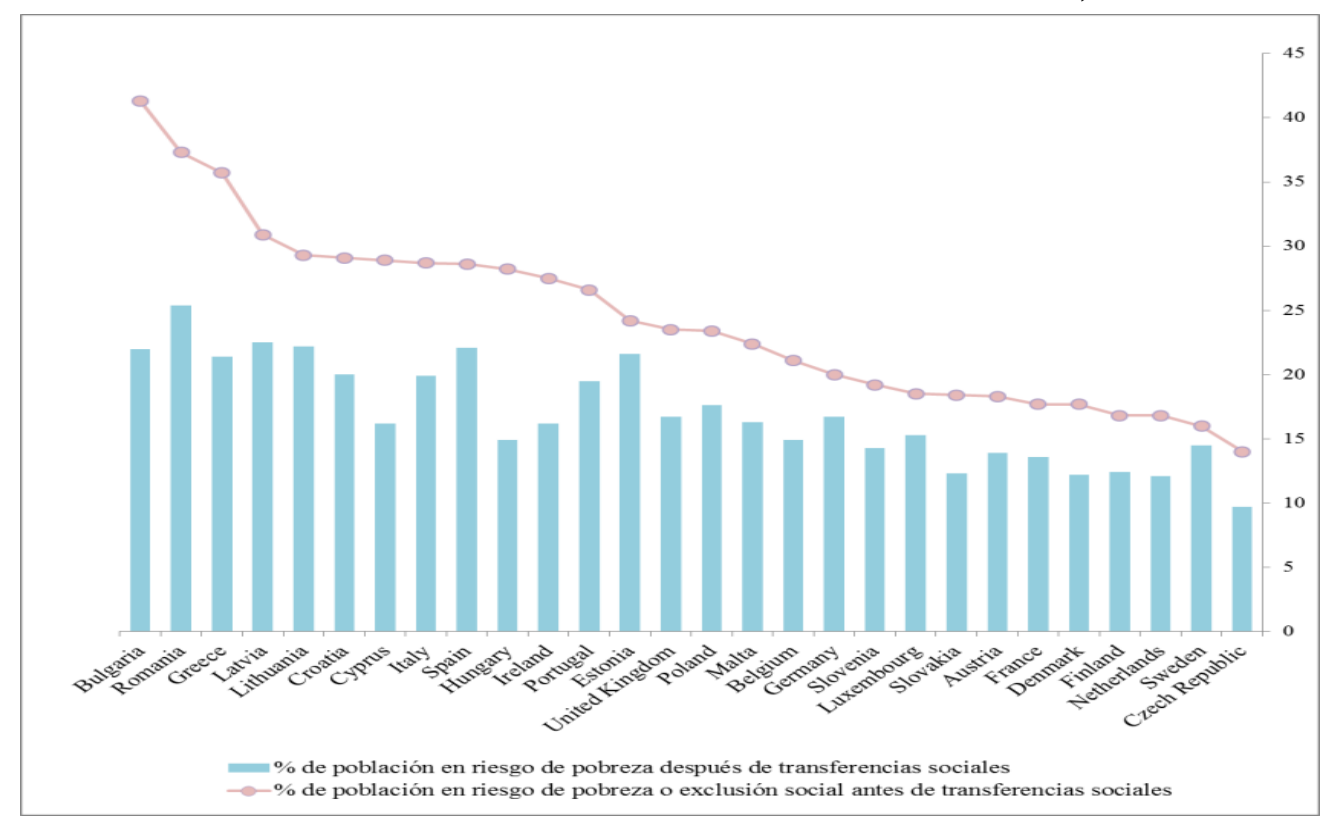

Fuente: Eurostat, operación estadística "People at risk of poverty after social transfers" Enlace: https://goo.gl/CXIt0l y operación estadística "People at risk of poverty or social exclusion" Enlace: https://goo.gl/Bsigzd. Elaboración propia.

En un estudio para el año 2000, Navarro (2004) utiliza como indicador del grado de desarrollo del Estado de Bienestar en un país, la cantidad de fondos públicos (transferencias, servicios públicos y otros gastos sociales) destinados a mejorar el bienestar de la población medidos como porcentaje del PIB. Según este indicador, España era el segundo país de la UE15 que destinaba menos recursos a gasto social, el 20.1 por 100, frente al promedio de la UE15 del 27.3. Solo Irlanda tenía un porcentaje menor, el 14.1, mientras que Suecia aportaba a gasto social el 32.3 por 100 de su PIB.

\footnotetext{
${ }^{1}$ Es el principal indicador de riesgo de pobreza o inclusión social contemplado en la Estrategia Europa 2020. Indica el porcentaje de población que vive en hogares cuya renta disponible total es inferior al umbral de riesgo de pobreza. Se considera que las personas están en riesgo de pobreza si su renta disponible equivalente, o renta por unidad de consumo, está por debajo del umbral oficial de riesgo de pobreza, fijado por la UE en el 60 por 100 de la mediana de la renta nacional disponible equivalente después de transferencias sociales
} 


\section{LA FELICIDAD ¿QUÉ ES?}

La felicidad es un constructo que depende de la percepción y el sentido de los seres humanos; es un concepto complejo, individual y difícil de cuantificar pues cada individuo construye su propia felicidad a partir de experiencias tanto sensoriales como materiales y estas son diferentes según la persona. Está demostrado que los seres humanos necesitan ser sociales para alcanzar la felicidad. Requieren de la construcción de redes sociales individuales y colectivas fuertes que les aporten confianza (seguridad en sí mismos), amor y afecto. Cada persona debe preparar y cultivar su propia felicidad ya que es una condición vital que depende de la conciencia individual y de la experiencia interna del individuo (Csikszentmihalyi, 2008). Para Savater (2012) la felicidad es lo que queremos que sea.

Existen distintos enfoques respecto a la felicidad. Así, Veenhoven (2005) diferencia entre la felicidad global o la de un área específica. La primera es la apreciación positiva de la vida en conjunto y la segunda la aportan la pareja, la familia, los amigos, el trabajo, la escuela, etc. Por su parte, Warr (2011) distingue dos tipos de felicidad. Una se construye mediante el bienestar y otra por la autorrealización personal; plantea que las personas no pueden autorrealizarse si no son felices trabajando. También diferencia la felicidad de forma temporal, de largo y de corto plazo. Una viene determinada por los rasgos de personalidad, relacionadas con la satisfacción laboral, la edad y el género (asociadas con el bienestar). La otra, se relaciona con la autoeficacia, la novedad, la relevancia personal y la situación socioeconómica individual; entre ellas, se encuentran la preocupación sobre quién soy, quién me gustaría ser y el cómo será mi futuro (Warr, 2013).

A pesar de la dificultad para medir la felicidad, se han encontrado variables por las que se puede analizar. Entre ellas se halla la satisfacción subjetiva que contempla que la felicidad es propia de cada individuo. "El comportamiento observado es un indicador incompleto para reconocer el bienestar individual. Aceptando esta visión, la felicidad individual puede ser capturada y analizada por medio de encuestas, en las que se pregunta qué tan satisfactoria es su vida, reconociendo de manera implícita al individuo como la fuente más acertada de información sobre la calidad de su vida” (Cruz y Torres, 2006; 135).

Desde el enfoque del bienestar, Helliwell y Putnam (2004) se centran en las relaciones como fuente del bienestar subjetivo. Principalmente en las relaciones de confianza, como las de parejas, familiares, amigos, vecinos y compañeros de trabajo. Asimismo, Pozos et al. (2013) plantean que los principales componentes para la felicidad son los que se desarrollan mediante lazos sociales cercanos o íntimos, como el amor y la familia.

En un estudio realizado por Cruz y Torres (2006) sobre la percepción de satisfacción de los colombianos, se puso de relieve que las variables sociales y geográficas son más significativas que las económicas para la satisfacción de los individuos. Se demostró que:

a) Los ingresos afectan a la percepción de satisfacción solo hasta conseguir un determinado nivel de renta a partir del cual van perdiendo importancia.

b) La educación es una variable importante para la satisfacción.

c) El estado de salud también es una variable influyente para explicar la percepción de satisfacción, no solo porque el individuo sea más productivo sino por el mejor aprovechamiento de su tiempo de ocio.

d) Ser propietario de una vivienda y el estado de la misma también son variables relevantes sobre la satisfacción. 
e) La edad y el sexo influyen en la satisfacción, las mujeres se encuentran menos satisfechas que los hombres y la curva de felicidad respecto a la edad presenta forma de U siendo el punto mínimo alrededor de 50 años.

f) No existen diferencias significativas en el grado de satisfacción por regiones.

g) Las características de los individuos con mejores niveles de satisfacción son: ser cabeza de familia, estar empleado, tener alto nivel de educación y buena salud.

Otros estudios, también, han demostrado que el nivel de bienestar subjetivo aumenta con el crecimiento de la renta, pero con rendimientos decrecientes. Igualmente muestran la existencia de una relación convexa entre edad y felicidad, así como con el nivel socioeconómico y el estatus familiar (Boisier, 2010). Díaz, Portela y Neira (2011; 26) también destacan como factores determinantes del bienestar subjetivo, el ingreso y el capital social. Para ellos "el ingreso se constituye como uno de los determinantes de lo que podríamos denominar, a modo de resumen, "calidad de vida". El análisis realizado para el capital social permite concluir el poder de las redes y de la confianza en los ciudadanos y en las instituciones como determinantes no sólo del crecimiento de las economías, sino también de la calidad de vida de los ciudadanos que las componen".

Otros autores han estudiado la cultura como variable que influye en el estado de felicidad de un individuo. Para estos existen diferencias en lo que una persona necesita para ser feliz dependiendo de su cultura (González, 2004; Csikszentmihalyi, 2008; Ott, 2016).

La economía y las ciencias sociales miden la felicidad de forma indirecta, aproximándola mediante la satisfacción, la calidad de vida o el grado de bienestar. Estos son indicadores evaluables que están determinados por la seguridad en el trabajo, como medio de obtener recursos para cubrir sus necesidades; la salud y la seguridad ciudadana.

Otros estudios se centran en los beneficios de la felicidad en el trabajo, y su relación con la productividad de los trabajadores, usando como indicador la satisfacción laboral, que es un rendimiento no monetario del trabajo. De esta forma, se realiza un análisis subjetivo de los fenómenos del mercado laboral (Angulo, Quejada y Yánez, 2012). En la misma línea, Dutschke (2013) destaca la importancia de conocer los factores que más influyen en la felicidad organizacional. Entre estos, los más sobresalientes son el reconocimiento, la posibilidad de desarrollo personal y profesional junto al ambiente interno. No se encuentra la retribución como en principio se podría pensar.

\section{PRODUCCIÓN, ESTADO DEL BIENESTAR Y FELICIDAD}

La estrategia Europa 2020 pretende lograr un crecimiento inteligente, mediante políticas que potencien y mejoren la educación, la investigación y la innovación; sostenible, favoreciendo una economía con bajas emisiones de carbono; e integrador, con el objeto de reducir el paro y la pobreza. Para alcanzar estos fines se centra en la consecución de cinco objetivos basados en el empleo, I+D, el cambio climático y la sostenibilidad energética, la educación y la lucha contra la pobreza y la exclusión social (Fresno, Renes y Tsolakis, 2012).

Consecuentemente, las políticas europeas han de ir dirigidas a conseguir producciones más competitivas apoyadas en la innovación y el desarrollo. Ello hace necesario una mejora del capital humano y social apoyada en la educación y la investigación. El concepto inicial clásico de capital humano, que abarcaba solo la perspectiva económica, se ha ampliado a aspectos sociales como la calidad y la duración de la vida, la felicidad, la inclusión social y la actividad social (Eurostat, 2016). La OCDE (2001) añade el conocimiento, las aptitudes, las competencias y otros atributos empleados en la creación del bienestar individual, social y económico. 
La teoría del capital humano considera el trabajo como medio de producción dependiente de las fuerzas económicas, se centra en la diferenciación de la población activa e introduce a las instituciones sociales básicas (educación y familia) en el análisis económico (Bowles y Gintis, 2014). Un trabajador feliz es más productivo, además, debe contar con otros factores como son unos conocimientos adecuados (educación), una buena salud (sanidad) y una satisfacción laboral alta.

Desde esta teoría se considera a la educación como una inversión relacionada de modo directo, entre otras variables, con la participación en el mercado laboral, la probabilidad de empleo, los ingresos, las condiciones de trabajo y la salud. Un nivel de educación más alto ayuda a obtener trabajos más autónomos, estimulantes, remunerados y con mayor participación en la toma de decisiones. Asimismo, las personas con una educación más alta tienen hábitos más saludables. Todo ello hace que la educación incida positivamente en la salud y en el bienestar individual (Salinas y Salinas, 2008).

Los gastos en educación han de dedicarse a la creación de habilidades o competencias (skills) para mejorar el capital humano, ya que son estas las que aumentan la productividad y la competitividad de las empresas. El mercado de trabajo ofrece y demanda habilidades, según Eurostat (2016) existen cuatro dimensiones para analizar dichas habilidades: la oferta (es la que aporta la mano de obra), la demanda (la que requieren los empleadores), el desajuste entre ellas y el desarrollo de las mismas.

El análisis del desajuste de las habilidades presenta dos dimensiones, la macro que analiza la brecha entre la oferta y la demanda de habilidades y la micro que es la desigualdad de competencia entre los trabajadores. Dentro del nivel micro se pueden presentar dos tipos de desajustes, el vertical y el horizontal. El primero, se apoya en la educación formal y los requisitos de trabajo y el segundo en el desajuste entre la educación de cada trabajador y los puestos de trabajo.

El ajuste completo de habilidades es difícil de conseguir como consecuencia del continuo desarrollo de las tecnologías y la introducción de nuevas innovaciones y, por tanto, del surgimiento de nuevas necesidades de habilidades. Si bien estos avances son necesarios para el desarrollo de los países, requieren de una actualización de las competencias de los trabajadores y de las empresas para corregir y reducir los nuevos desajustes.

El desarrollo de estas habilidades ha de adquirirse mediante la formación profesional y la educación en adultos. La educación, tanto la formal como la continua, se puede realizar de tres formas: pública, privada o mixta. Tanto el primer caso como el último requieren de un Estado de Bienestar que las financien mediante recursos públicos que beneficien tanto a los trabajadores como a las empresas.

Pacek y Radcliff (2008) defienden que el Estado de Bienestar contribuye a mejorar el bienestar subjetivo y evita que los seres humanos se conviertan en mercancías. Sostienen que el neoliberalismo convierte a las personas, "prisioneras de su egoísmo", en insatisfechas e individualistas; puesto que el ser humano para dar sentido a su vida necesita ser social y construir relaciones de confianza recíprocas. En esta línea, Easterlin (2013) afirma que el pleno empleo y una sociedad generosa con la protección social aumentan la felicidad humana. Su estudio muestra que:

a) Los países que cuentan con mayores tasas de crecimiento económico no son los que incrementan más la felicidad.

b) Realizar políticas de empleo y de protección social aumentan la felicidad.

c) Todos los países pueden afrontar la realización de políticas de empleo y de protección social. 
Para Bergqvist, Yngwe y Lundberg (2013) las políticas de protección social y prestación de servicios proporcionadas por un Estado de Bienestar son más importantes para los que tienen menos recursos y ayudan a la protección de las desigualdades en materia salud, de educación, de acceso al ocio, etc. La salud de los trabajadores es importante en el mercado laboral y aumenta la productividad. En este sentido, resulta esencial la prevención mediante la disponibilidad de servicios sanitarios, la realización regular de actividad física que contribuye a aumentar la salud, los logros educativos, el bienestar humano, las competencias personales, la calidad y nivel de vida (Bailey et al., 2013). La World Health Organization (2013) sostiene que la mala salud socava el desarrollo económico de los países y aumenta las desigualdades a escala mundial, regional y nacional.

\section{METODOLOGÍA Y ANÁLISIS}

Siguiendo a Navarro (2004), el Estado de Bienestar engloba todas las intervenciones de los países dirigidas a mejorar el bienestar social y la calidad de vida de la población. De esta forma, para medir y caracterizar el grado desarrollo del Estado de Bienestar en los países de la UE, se consideran los gastos públicos que, de modo más directo y en mayor medida, afectan a la satisfacción de la población con su vida.

\subsection{Metodología, marco conceptual y empírico y fuentes}

En este trabajo se ha realizado un análisis exploratorio de los datos para caracterizar los rasgos principales de la distribución de los gastos y prestaciones públicas de tipo social en los países de la UE, asociados al grado de bienestar subjetivo de los ciudadanos y a la renta per cápita.

Además, se han aplicado algunos modelos de regresión para estructurar el comportamiento de la felicidad de los países en función de las inversiones en servicios públicos y las transferencias sociales de los gobiernos, así como de la producción per cápita.

La felicidad se asocia positivamente con el gasto público de tipo social por las mejoras en el bienestar social y la calidad de vida de la población. Desde este supuesto, mayor inversión en servicios y prestaciones públicas contribuirán a elevar de modo estable el bienestar subjetivo de los ciudadanos. Sin embargo, los distintos tipos de servicios y prestaciones sociales pueden producir diferentes impactos sobre la felicidad subjetiva, que son susceptibles de medirse empíricamente.

Por ello, se han estimado modelos de regresión para tratar de caracterizar la influencia de las clases de gastos públicos sociales sobre las ganancias de felicidad subjetiva, o satisfacción con la vida de la población. El modelo formal del estudio se apoya en la función de felicidad subjetiva:

$Y=f(X, Z)+e$

Donde $Y$ representa la satisfacción con la vida, $X$ un grupo de variables asociadas a los gastos por habitante de los gobiernos en servicios y prestaciones públicas, $Z$ la disponibilidad de renta y e es el término de error.

La siguiente función proporciona la contrapartida empírica de la

$$
L s_{i}=\beta_{1}+\beta_{2} G_{s_{P C}}+\beta_{3} P_{P B} B_{P C_{i}}+e_{i}
$$

Donde $L s$ indica la satisfacción con la vida, $\left(G s_{P C}\right)$ los gastos sociales de los gobiernos por habitante y $\left(P I B_{P C}\right)$ el producto interior bruto por habitante en el país $i$, en cada caso. 
Se han aplicado regresiones con los distintos tipos de gasto social para medir cómo afectan al grado de felicidad. Las estimaciones se han realizado mediante el método de mínimos cuadrados ordinarios (OLS).

Los datos utilizados se han extraído de la oficina de estadísticas de la Unión Europea, Eurostat y de la Organización Europea para la Cooperación al Desarrollo (OECD). Para el Estado de Bienestar, los procedentes de la operación estadística General Government Expenditure by Function ${ }^{2}$ permiten efectuar comparaciones entre países sobre la distribución de los gastos sociales y de la protección social. Para medir la felicidad se ha utilizado como indicador, la variable satisfacción con la vida, componente del indicador de bienestar social better live index elaborado por la $\mathrm{OECD}^{3}$ cuyos valores oscilan de 0 a 10 , indicando el grado de felicidad subjetiva en sentido ascendente. Asimismo, el indicador utilizado como medida de la producción per cápita por país ha sido el $P I B_{P C}$. Los datos este indicador también proceden de Eurostat. Se ha trabajado con datos de 2014 ${ }^{4}$.

El Eurostat clasifica el gasto público según las funciones del gobierno, abreviadas como $\mathrm{COFOG}^{5}$, conforme a los criterios del SEC. La clasificación tiene tres niveles de detalle: divisiones, grupos y clases. Las divisiones describen los objetivos generales del gobierno, mientras que los grupos y las clases definen los medios por los cuales se alcanzan estos objetivos generales.

En este trabajo se han utilizado las divisiones que recogen los gastos que contribuyen de modo directo a aumentar el bienestar social y la calidad de vida de la población (Navarro, 2004). Es decir, los de servicio público o transferencia social. No se han tenido en cuenta los de defensa, orden público, asuntos económicos, ni protección del medio ambiente. El anexo 1 muestra la relación de los tipos de gasto público considerados en esta investigación y sus componentes.

En el cuadro siguiente se indican las divisiones de gasto utilizadas y sus abreviaturas.

\begin{tabular}{r|l|l} 
& Gastos públicos totales & $G g$ \\
\hline & $\bullet$ Servicios públicos generales & $S p$ \\
& $\bullet$ Vivienda y servicios comunitarios & $V s C$ \\
Divisiones o & $\bullet$ Salud & $S d$ \\
funciones de los & $\bullet$ Ocio, cultura y religión & $O c r$ \\
gastos públicos & $\bullet$ Educación & $E d$ \\
& $\bullet$ Protección social & $P s$ \\
& $\bullet$ Gastos sociales totales & $G s$ \\
\hline
\end{tabular}

\footnotetext{
${ }^{2}$ Eurostat. Operación estadística: General government expenditure by function (COFOG) (gov_10a_exp). Enlace https://goo.gl/7d8kXK.

${ }^{3}$ Indicador del grado de bienestar de las personas elaborado desde una perspectiva multidimensional. Recoge distintos aspectos esenciales en las condiciones de vida materiales y la calidad de vida de las personas. De este modo abarca la vivienda, el ingreso familiar, el empleo, la comunidad, la educación, el medioambiente, el compromiso cívico, la salud, la satisfacción, la seguridad y el equilibrio vida- trabajo.

https://www.oecdregionalwellbeing.org/.http://www.oecd-ilibrary.org/economics/como-va-la-vida-

2015_9789264240735-es. Enlace a datos en http://stats.oecd.org/Index.aspx?DataSetCode=BLI

${ }^{4}$ Enlace a datos en http://appsso.eurostat.ec.europa.eu/nui/show.do?dataset=nama_10_gdp\&lang=en a fecha de 13/12/2016.

${ }^{5}$ Esta clasificación fue desarrollada en su versión actual en 1999 por la Organización para la Cooperación y el Desarrollo Económico y publicada por la División de Estadística de las Naciones Unidas como un estándar que clasifica los propósitos de las actividades gubernamentales.
} 
En el estudio de la felicidad, no hay datos disponibles de los 28 países considerados, tan sólo de 21. En consecuencia, para el cálculo de las medidas de correlación y las estimaciones de los modelos de regresión lineal se han tenido en cuenta solo las observaciones de los países con datos; dejando fuera del análisis a Bulgaria, Croacia, Chipre, Letonia, Lituania, Malta y Rumania.

\subsection{Análisis de la distribución del gasto social en la UE en el año 2014}

El análisis efectuado ha mostrado que los gastos sociales presentan pesos relativos diferentes en los Presupuestos Generales de Gasto de los países de la UE con porcentajes que oscilan entre el 72.3 por 100 (Rumanía) y el 88.7 por 100 (Dinamarca). Consecuentemente, existen diferentes Estados de Bienestar en la Unión Europea (mapa 1, gráfico 2).

\section{MAPA 1. PORCENTAJES DE GASTO SOCIAL EN EL CONJUNTO DE GASTOS PÚBLICOS. UE, 2014}

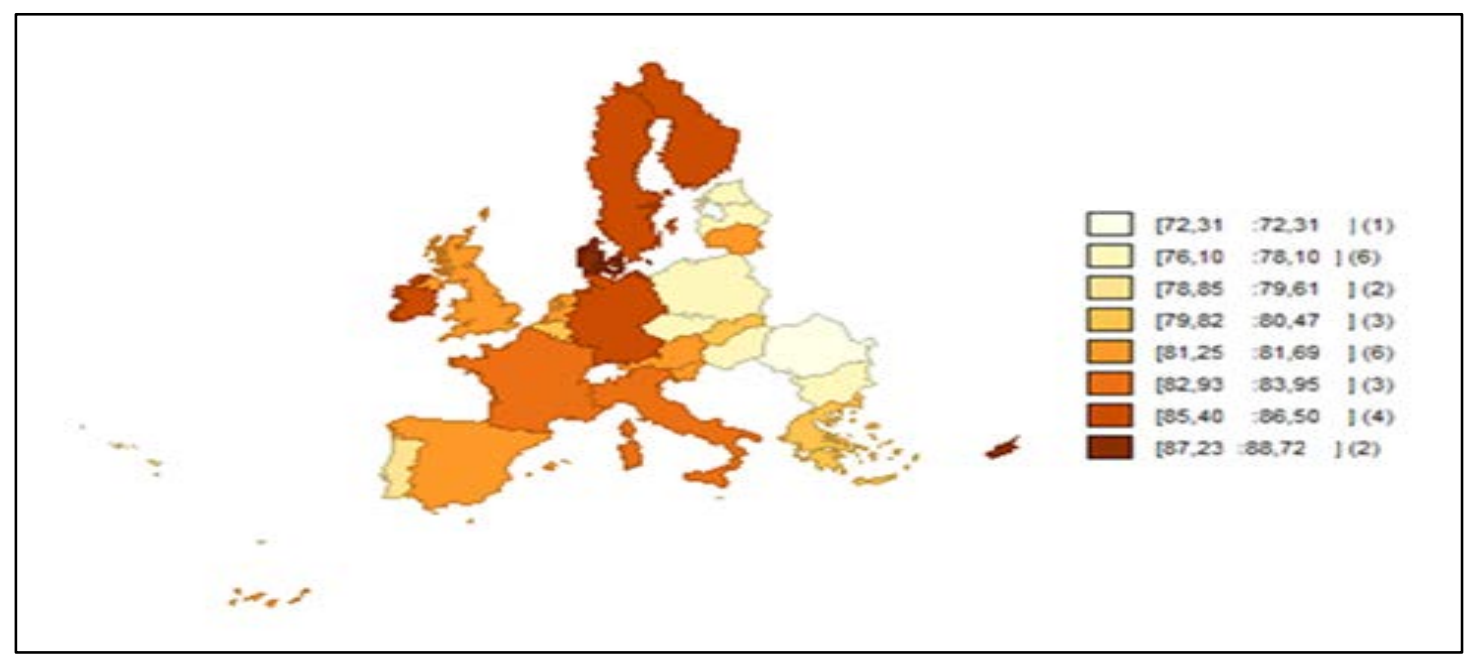

Nota: Los intervalos expresan los porcentajes en cada clase. El número entre paréntesis indica el número de países en cada clase.

Fuente: Eurostat. Operación estadística: General government expenditure by function (COFOG) (gov_10a_exp). Enlace https://goo.gl/7d8kXK._Elaboración propia.

\section{GRÁFICO 2. PORCENTAJE DE GASTO SOCIAL EN LA UE EN 2014 (GASTO PÚBLICO=100) DIAGRAMA DE CAJA}

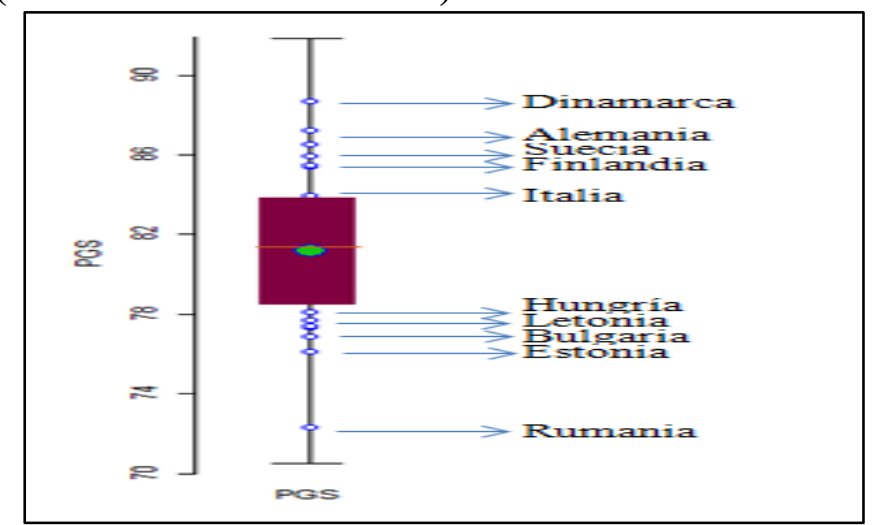

Fuente: Eurostat, Operación estadística: General government expenditure by function (COFOG) (gov_10a_exp). Enlace https://goo.gl/7d8kXK. Elaboración propia. 
Se observa que las naciones del Norte y del Centro de Europa ${ }^{6}$ dedican las mayores proporciones del total de gasto público a gastos sociales, por tanto, son los territorios con un Estado de Bienestar más desarrollado. Así, Dinamarca aplica cantidades superiores al promedio de la UE en un 7 por 100; les siguen de Finlandia, Suecia, Irlanda, Alemania (3 por 100), e Italia y Francia (1 por 100). En el punto medio se encuentra Luxemburgo. Por debajo del promedio, con proporciones de gasto social inferiores entre el 2 y el 13 por 100, se observan a Reino Unido, España, Países Bajos, Austria y, en menor medida, a Grecia, Portugal y de los países de la Europa Oriental (cuadro 1).

\begin{tabular}{|c|c|c|c|c|c|c|c|c|}
\hline & $\boldsymbol{G g}$ & $s p$ & Vsc & $S d$ & OCR & Ed & Ps & Gs \\
\hline Denmark & 1,00 & 0,93 & 0,29 & 1,04 & 1,50 & 1,25 & 1,08 & 1,07 \\
\hline Cyprus & 1,00 & 2,77 & 3,21 & 0,36 & 0,84 & 1,16 & 0,62 & 1,05 \\
\hline Finland & 1,00 & 1,03 & 0,48 & 0,95 & 1,17 & 1,07 & 1,08 & 1,04 \\
\hline Sweden & 1,00 & 1,08 & 1,05 & 0,90 & 1,00 & 1,24 & 1,02 & 1,03 \\
\hline Ireland & 1,00 & 1,14 & 1,32 & 1,33 & 0,93 & 1,09 & 0,86 & 1,03 \\
\hline Germany & 1,00 & 1,03 & 0,64 & 1,08 & 0,86 & 0,95 & 1,05 & 1,03 \\
\hline Italy & 1,00 & 1,25 & 0,91 & 0,93 & 0,67 & 0,77 & 1,04 & 1,01 \\
\hline France & 1,00 & 0,83 & 1,76 & 0,95 & 1,19 & 0,94 & 1,07 & 1,01 \\
\hline European Union (28) & 1,00 & 1,00 & 1,00 & 1,00 & 1,00 & 1,00 & 1,00 & 1,00 \\
\hline Luxembourg & 1,00 & 0,76 & 0,94 & 0,76 & 1,36 & 1,22 & 1,10 & 1,00 \\
\hline United Kingdom & 1,00 & 0,88 & 1,01 & 1,15 & 0,71 & 1,15 & 0,93 & 0,98 \\
\hline Spain & 1,00 & 1,12 & 0,78 & 0,91 & 1,22 & 0,89 & 0,98 & 0,98 \\
\hline Slovenia & 1,00 & 1,08 & 1,25 & 0,88 & 1,59 & 1,16 & 0,90 & 0,98 \\
\hline Netherlands & 1,00 & 0,81 & 0,70 & 1,18 & 1,48 & 1,14 & 0,91 & 0,98 \\
\hline Austria & 1,00 & 0,94 & 0,49 & 1,00 & 1,08 & 0,92 & 1,01 & 0,98 \\
\hline \begin{tabular}{|l|} 
Lithuania \\
\end{tabular} & 1,00 & 0,96 & 0,68 & 1,06 & 1,21 & 1,51 & 0,82 & 0,98 \\
\hline Belgium & 1,00 & 1,09 & 0,48 & 0,98 & 1,08 & 1,12 & 0,90 & 0,97 \\
\hline \begin{tabular}{|l|} 
Slovakia \\
\end{tabular} & 1,00 & 0,98 & 1,04 & 0,30 & 1,05 & 0,97 & 1,19 & 0,96 \\
\hline Greece & 1,00 & 1,42 & 0,29 & 0,62 & 0,57 & 0,86 & 1,00 & 0,96 \\
\hline \begin{tabular}{|l|} 
Portugal \\
\end{tabular} & 1,00 & 1,22 & 0,81 & 0,80 & 0,82 & 1,17 & 0,89 & 0,96 \\
\hline $\begin{array}{l}\text { Croatia } \\
\end{array}$ & 1,00 & 1,33 & 1,03 & 0,93 & 1,31 & 0,96 & 0,81 & 0,95 \\
\hline Malta & 1,00 & 1,18 & 0,56 & 0,93 & 1,19 & 1,32 & 0,79 & 0,95 \\
\hline Poland & 1,00 & 0,85 & 1,19 & 0,73 & 1,31 & 1,22 & 0,95 & 0,94 \\
\hline Hungary & 1,00 & 1,46 & 1,25 & 0,67 & 1,88 & 1,01 & 0,77 & 0,94 \\
\hline Czech Republic & 1,00 & 0,81 & 1,44 & 1,20 & 1,30 & 1,19 & 0,77 & 0,93 \\
\hline Latvia & 1,00 & 0,95 & 2,08 & 0,68 & 2,13 & 1,54 & 0,76 & 0,93 \\
\hline Bulgaria & 1,00 & 1,07 & 2,73 & 0,87 & 1,65 & 0,95 & 0,79 & 0,93 \\
\hline Estonia & 1,00 & 0,75 & 0,83 & 0,90 & 2,45 & 1,43 & 0,77 & 0,92 \\
\hline Romania & 1,00 & 0,97 & 2,33 & 0,77 & 1,28 & 0,84 & 0,81 & 0,87 \\
\hline
\end{tabular}

Nota: Gastos públicos totales (Gg) ; Servicios públicos generales ( $\mathrm{Sp}$ ); Vivienda y servicios comunitarios (Vsc); Salud (Sd); Ocio, cultura y religión (OCR ); Educación ( Ed ); Protección social (Ps); Gastos sociales totales (Gs.) Fuente: Eurostat. Operación estadística: General government expenditure by function (COFOG) (gov_10a_exp). Enlace https://goo.gl/7d8kXK. Elaboración propia.

Asimismo, se aprecia una importante asociación entre la proporción de gasto social de los países y la estructura de la población dependiente. Así, en algunos grupos como Alemania, Italia, Finlandia o Suecia queda reflejado el envejecimiento de la población al observarse un elevado peso relativo de gasto social junto a elevados porcentajes de población de más de 65

\footnotetext{
${ }^{6}$ Chipre destaca una proporción de gasto social superior en el 5 por 100 al promedio; sin embargo, al observar su distribución se aprecia que destina la mayor parte del mismo a servicios públicos generales y muy poco a la protección social, la sanidad o la educación. Por lo que no parece prudente incluirlo entre los países con Estado de Bienestar más fuerte.
} 
años y bajos de menos de 15 años. Mientras que en otros el porcentaje de gasto social se presenta vinculado a un elevado peso demográfico de población menor de 15 años, como por ejemplo Irlanda. Otros como son el caso de Francia y Reino Unido presentan prácticamente las mismas proporciones en gasto social población de más de 65 y de menos de 15 (gráfico 3).

\section{GRÁFICO 3. ASOCIACIÓN ENTRE PORCENTAJES DE GASTO SOCIAL Y ESTRUCTURAS DEMOGRÁFICAS. GASTO PÚBLICO=100. UE, 2014.}
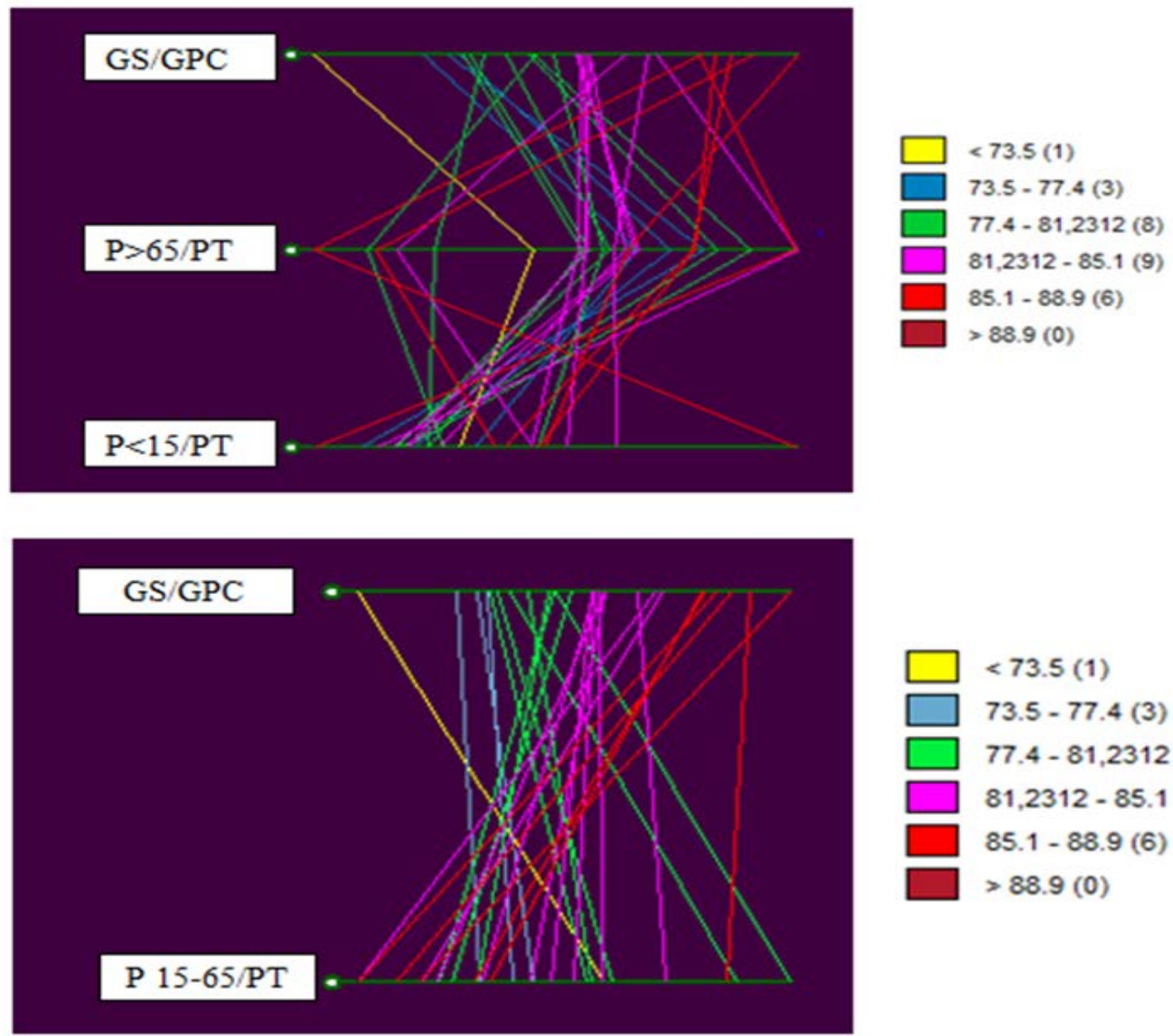

$<73.5$ (1)

$73.5-77.4(3)$

$77.4-81,2312(8)$

$81,2312-85.1(9)$

$85.1-88.9(6)$

$>88.9(0)$

Nota: GS: Gasto social; GPC: Gasto Público; P>65: Población de más de 65 años; P<15: Población de menos de 14 años; PT: Población toral; P 15-65: Población entre 15 y 65.

Nota: Los intervalos expresan los porcentajes de cada magnitud en cada clase. El número entre paréntesis indica el número de países en cada clase.

Fuente: Eurostat. Operación estadística: General government expenditure by function (COFOG) (gov_10a_exp). Enlace https://goo.gl/7d8kXK. Elaboración propia.

Las mayores asociaciones directas entre el gasto social y la población entre 15 y 65 años (población activa) se producen en países de Europa Oriental como Eslovaquia, Chipre, Polonia, Hungría o Rumanía. Estos presentan tasas de población activa (entre 70.6 y 68.3 por 100), superiores a la media europea (66.2 por 100); junto a menores tasas de envejecimiento (entre el 13.5 y el 17.4 por 100 frente al 18.4 del promedio europeo). En el resto de países, se aprecia cómo a valores altos del peso de gasto en protección social les corresponden valores bajos en el porcentaje de población activa y viceversa en un número importante de países; este dato confirma la asociación entre el gasto social y la atención a la dependencia.

Por funciones, las principales partidas del gasto social en todos los países se destinan a protección social, acapara entre el 60.2 y el 28.7 por 100 de los mismos; les siguen con menor 
importancia los servicios públicos generales, la sanidad y la educación. Igualmente, la protección social sobresale entre el total de los gastos públicos en la Unión Europea con una media del 40.4 por 100. Destacan Eslovaquia (48.1 por 100); seguida de los países del Norte de Europa, Luxemburgo, Dinamarca y Finlandia (44.2, 43.8 y 43.8 por 100, respectivamente); y de otros países como Francia, Alemania, Italia, Austria y Suecia (entre 46.1 y 40.9 por 100), la mayoría del centro de Europa. En torno a la media europea se encuentran Grecia y España. Por debajo del promedio se hallan Reino Unido, Bélgica, Países Bajos, Portugal, Irlanda y los países de Europa Oriental (gráfico 4).

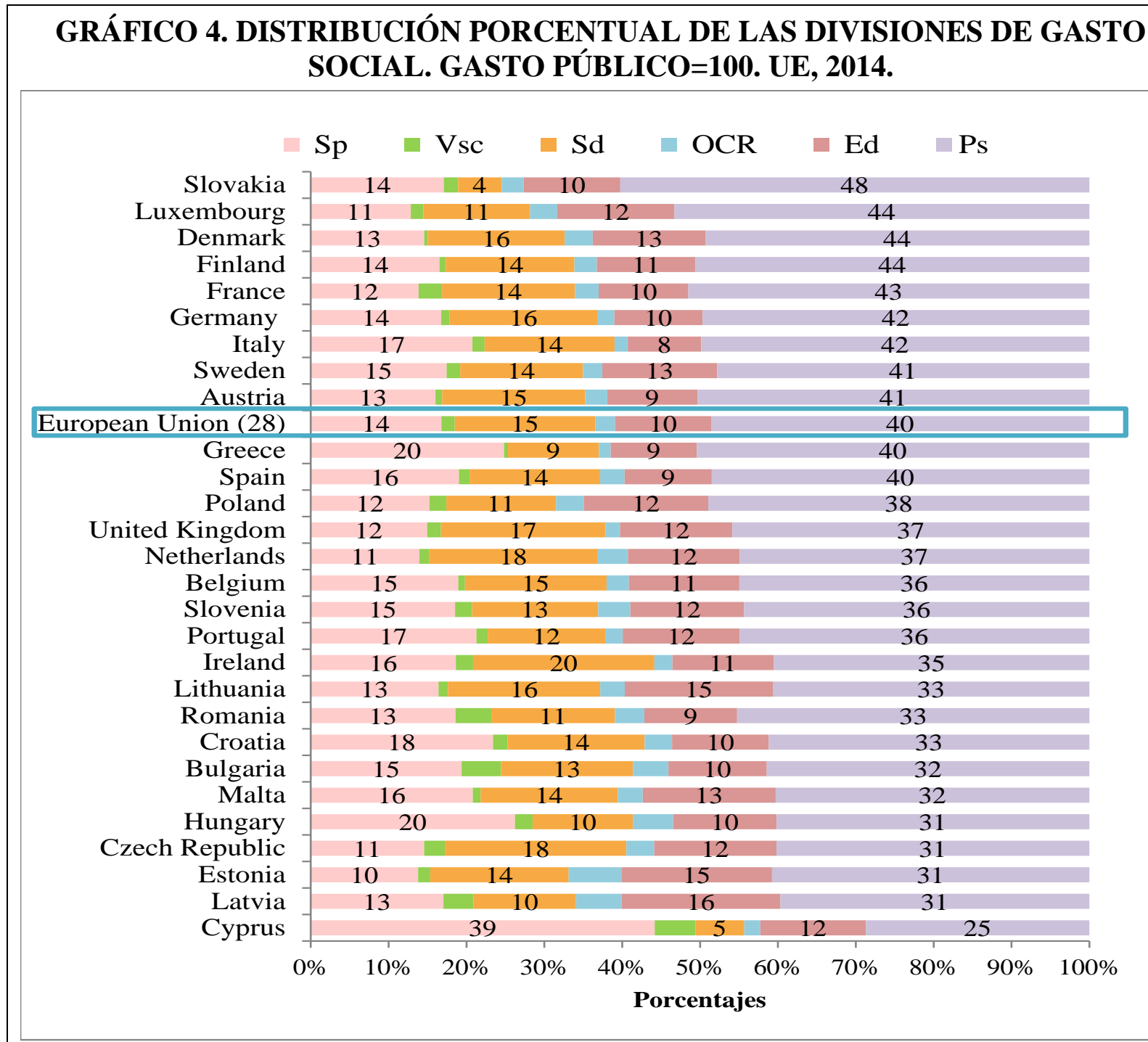

Nota: Servicios públicos generales ( Sp ); Vivienda y servicios comunitarios (Vsc); Salud (Sd ); Ocio, cultura y religión (OCR ); Educación ( Ed ); Protección social (Ps)

Fuente: Eurostat. Operación estadística: General government expenditure by function (COFOG) (gov_10a_exp). Enlace https://goo.gl/7d8kXK. Elaboración propia.

A los gastos sanitarios, los países europeos destinan entre el 23.3 y el 5.6 por 100 . Por encima de la media europea (18.1 por 100) se encuentran la Republica Checa, seguida de Irlanda, Países Bajos, Reino Unido, Lituania, Alemania, Austria y Bélgica, que presentan porcentajes de entre el 23.3 y el 18.2 por 100. Inmediatamente por debajo de la media, entre el 
17.8 y el 11.7 por 100, se hallan el resto de países, destacando el bajo porcentaje de gasto sanitario en Chipre y Eslovaquia (6.3 y 5.6 por 100, respectivamente).

En educación el gasto oscila entre el 20.4 y el 9.4 por 100 del gasto social en las naciones europeas. Los países de Europa Oriental son los que mayor proporción de gastos sociales destinan a educación, con porcentajes entre el 20.4 de Letonia y el 12.4 de Eslovaquia, superiores al promedio europeo del 12.3 por 100. Los países del Norte también presentan importantes gastos relativos en educación; el 14.7 en Suecia, el 14.5 en Dinamarca, y el 12.7 por 100 en Finlandia. Igualmente, Reino Unido, Irlanda y los países del Centro de Europa presentan porcentajes superiores a la media entre el 14.4 y el 13.0 por 100. Los países con proporciones de gasto en educación por debajo del promedio son Rumanía, Austria, Francia, Alemania, España, Grecia e Italia, que muestran porcentajes entre el 11.9 de Rumanía y el 9.4 por 100 de Italia (mapa 2).

\section{MAPA 2. DISTRIBUCIÓN ESPACIAL DE LOS TIPOS DE GASTOS SOCIALES. PORCENTAJES UE, 2014}

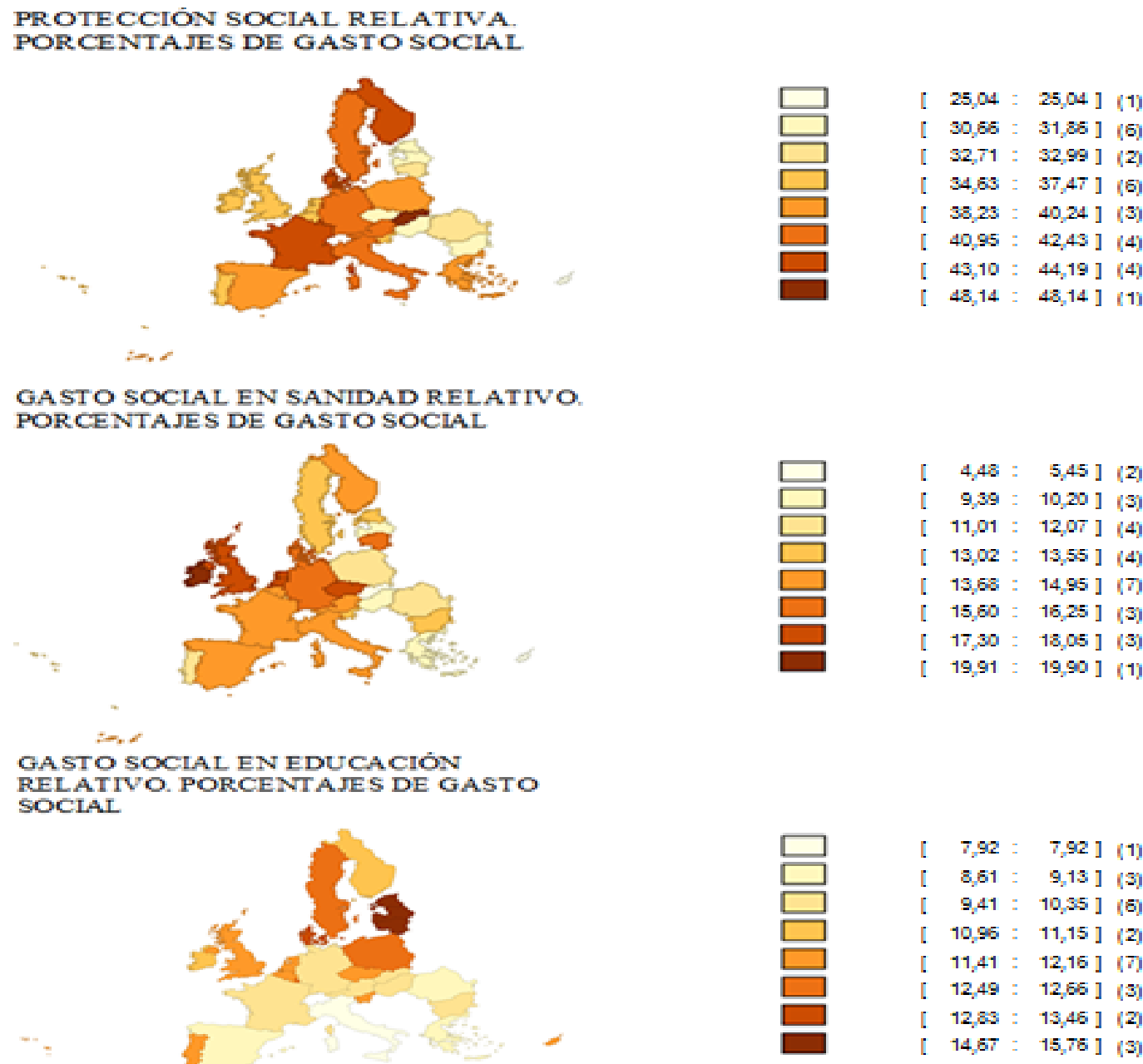

Nota: Los intervalos expresan los porcentajes de cada magnitud en cada clase. El número entre paréntesis indica el número de países en cada clase.

Fuente: Eurostat. Operación estadística: General government expenditure by function (COFOG) (gov_10a_exp). Enlace https://goo.gl/7d8kXK. Elaboración propia. 
El análisis del gasto social per cápita de los países de la Unión Europea pone de relieve una distribución desigual. Se observan varias pautas espaciales. Así, Luxemburgo destaca con 31462 euros, 2.9 veces el promedio europeo de 11024 euros. Asimismo, sobresalen los países nórdicos, Dinamarca, Suecia y Finlandia (22995, 19859 y 18924 euros, respectivamente) que destinan al gasto social por habitante cantidades superiores en 2.1, 1.8 y 1.7 veces a la media. Igualmente, superan el promedio los países del Centro y Este de Europa Austria, Bélgica, Francia, Países Bajos, Alemania. Irlanda y Reino Unido, con cantidades que oscilan entre 16673 y 12592 euros anuales (de 1.5 a 1.1 veces la media). Los países del Sur presentan valores inferiores a la media, excepto Italia que se encuentra ligeramente por encima del promedio. El gasto social por habitante de Chipre, España, Grecia y Portugal se sitúan entre 8500 y 6418 euros; entre un 20 y un 40 por 100 menos que la media. Los países de Europa Oriental ofrecen las menores cifras de gasto social por habitante, con cantidades de entre los 4849 (República Checa) y los 1897 euros (Rumania); entre un 60 y 80 por 100 inferior al promedio europeo (mapa 3).

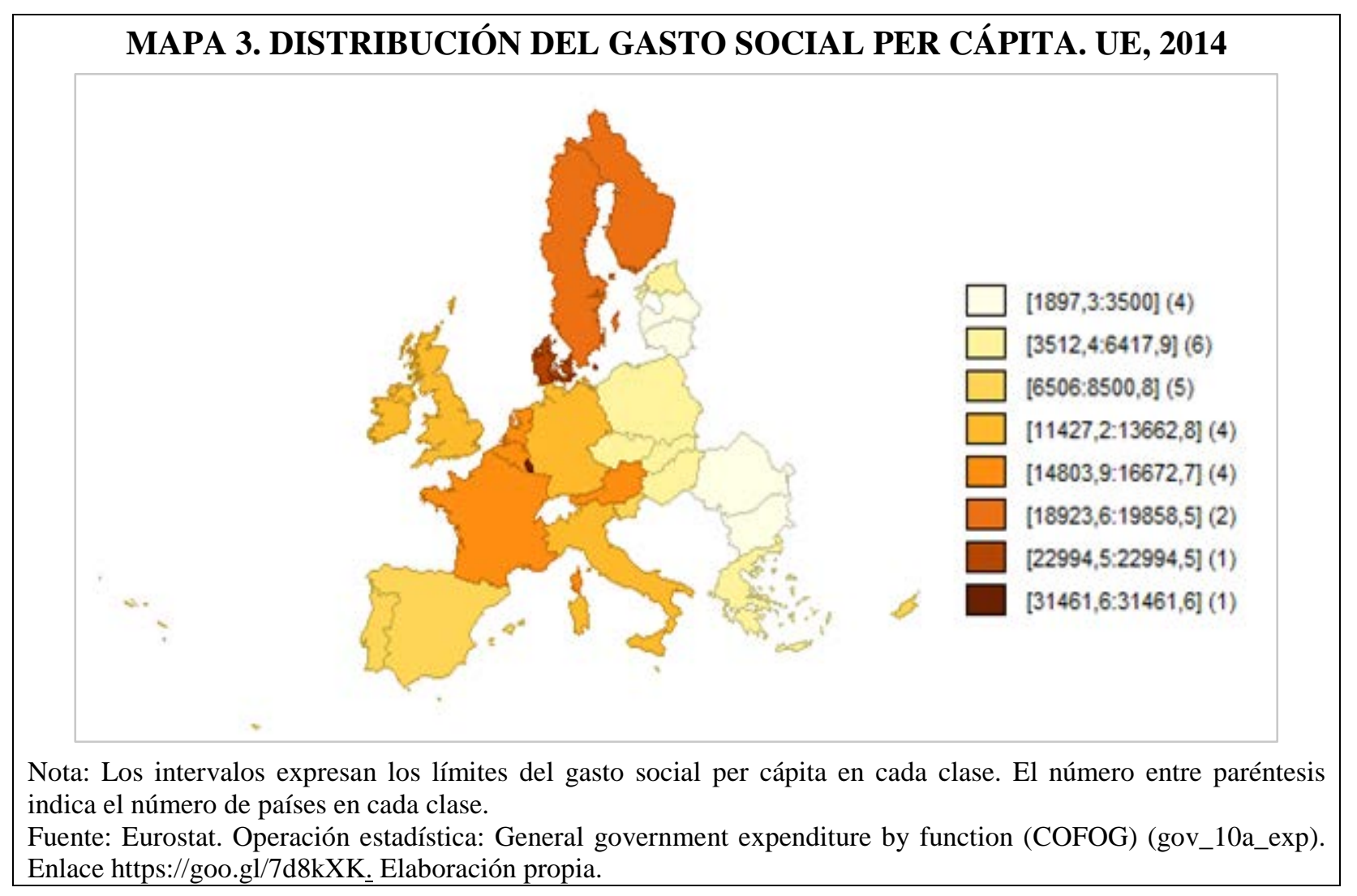

\subsection{Análisis del Estado de Bienestar como garante de la felicidad en la UE}

Los países de la Unión Europea ${ }^{7}$ observan un valor medio de 6.7 en el indicador de la felicidad cuyas estimaciones oscilan entre el 7.6 de Dinamarca y el 4.7 de Grecia. La distribución espacial del bienestar subjetivo en Europa pone de relieve un patrón heterogéneo que se aproxima en gran medida a la del gasto público por habitante (mapa 4).

\footnotetext{
${ }^{7}$ Excepto Bulgaria, Croacia, Chipre, Letonia, Lituania, Malta y Rumania por no disponer de datos sobre el indicador de felicidad 2014.
} 


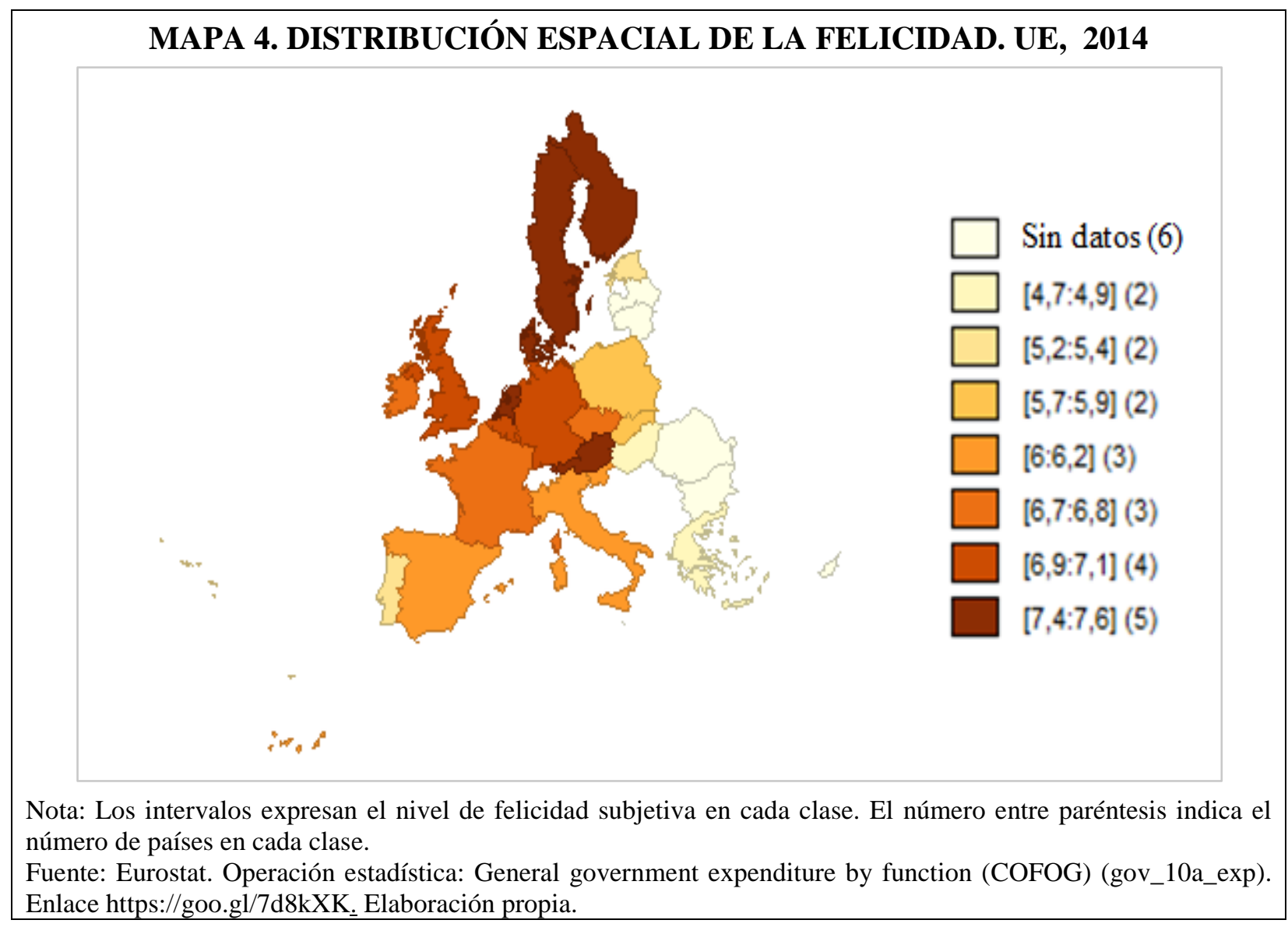

El Norte de Europa (Dinamarca, Austria, Países Bajos, Finlandia y Suecia) presenta las mayores cotas de felicidad subjetiva con valores entre 7.6 y 7.4, seguido del Centro de Europa (Bélgica, Luxemburgo y Alemania) con niveles de 7.1 a 7.0; les siguen Reino Unido, Irlanda, República Checa y Francia, con valores en torno al promedio. Por debajo de la media se encuentran España e Italia, el resto de países del sur y los de Europa oriental que registran las menores evaluaciones con niveles de 4.7 a 5.9 .

Con el interés de relacionar la felicidad con el gasto social, sus componentes y la renta, se han especificado modelos de regresión que permiten analizar los factores que influyen en la felicidad o grado de bienestar subjetivo de los ciudadanos en los países de la Unión Europea. Estudiadas las correlaciones entre el indicador de felicidad, los gastos sociales por habitantes y el PIB per cápita, se han observado importantes correlaciones positivas, muy significativas todas ellas (cuadro 2).

La felicidad se encuentra directa y altamente relacionada con los gastos sociales (0.76). Entre estos gastos los más correlacionados son los destinados a salud (0.87), a educación (0.73) y a prestaciones sociales (0.73). A la hora de tratar de modelizar el comportamiento de la felicidad en función de estos gastos sociales se observan coeficientes de correlación por encima del 0.90 en todos los casos. De este modo, se han elaborado modelos de regresión simple para medir el impacto individual de cada una de las variables, pues no es posible el tratamiento conjunto por problemas de multicolinealidad.

Las estimaciones muestran que el gasto público en salud es la variable con mayor impacto sobre el promedio de felicidad subjetivo; aumentos de 1.000 euros en el gasto en salud, incrementan el indicador de felicidad en 0.63 unidades (Estimación 2). Le sigue el gasto público en educación, una subida de 1000 euros en este gasto produce un crecimiento de 
la felicidad en 0.61 unidades (estimación 4); aunque este modelo tiene menos capacidad explicativa que la anterior.

\begin{tabular}{|c|c|c|c|c|c|c|c|c|}
\hline \multicolumn{9}{|c|}{ CUADRO 2. COEFICIENTES DE CORRELACIÓN. UE, 2014} \\
\hline \multicolumn{2}{|c|}{$L S$} & Sp_pc & Vsc_pc & $S d \_p c$ & $O C R \_p c$ & \multirow{2}{*}{ Ed_pc } & \multirow[t]{2}{*}{$P S \_p c$} & \multirow{2}{*}{ Gs_pc Pib_PC } \\
\hline$L S$ & 1 & & & & & & & \\
\hline$S p \_p c$ & $\begin{array}{r}0.716 \\
0.0002 \\
\end{array}$ & 1 & & & & & & \\
\hline$V s c \_p c$ & $\begin{array}{c}0.46 \\
0.0192\end{array}$ & $\begin{array}{c}0.59 \\
0.0025\end{array}$ & 1 & & & & & \\
\hline$S d \_p c$ & $\begin{array}{c}0.87 \\
0.0000\end{array}$ & $\begin{array}{c}0.92 \\
0.0000\end{array}$ & $\begin{array}{c}0.62 \\
0.0013\end{array}$ & 1 & & & & \\
\hline$O C R \_p c$ & $\begin{array}{c}0.67 \\
0.0005\end{array}$ & $\begin{array}{c}0.80 \\
0.0000\end{array}$ & $\begin{array}{c}0.60 \\
0.0020\end{array}$ & $\begin{array}{c}0.84 \\
0.0000\end{array}$ & 1 & & & \\
\hline$E d \_p c$ & $\begin{array}{c}0.73 \\
0.0001 \\
\end{array}$ & $\begin{array}{c}0.90 \\
0.0000\end{array}$ & $\begin{array}{c}0.67 \\
0.0005\end{array}$ & $\begin{array}{c}0.91 \\
0.0000\end{array}$ & $\begin{array}{c}0.94 \\
0.0000\end{array}$ & 1 & & \\
\hline$P s \_p c$ & $\begin{array}{c}0.73 \\
0.0001 \\
\end{array}$ & $\begin{array}{c}0.93 \\
0.0000\end{array}$ & $\begin{array}{c}0.68 \\
0.0004\end{array}$ & $\begin{array}{c}0.91 \\
0.0000\end{array}$ & $\begin{array}{c}0.92 \\
0.0000\end{array}$ & $\begin{array}{c}0.97 \\
0.0000\end{array}$ & 1 & \\
\hline Gs_pc & $\begin{array}{c}0.76 \\
0.0000 \\
\end{array}$ & $\begin{array}{c}0.95 \\
0.0000\end{array}$ & $\begin{array}{c}0.68 \\
0.0004\end{array}$ & $\begin{array}{c}0.95 \\
0.0000\end{array}$ & $\begin{array}{c}0.92 \\
0.0000\end{array}$ & $\begin{array}{c}0.98 \\
0.0000\end{array}$ & $\begin{array}{c}0.99 \\
0.0000\end{array}$ & 1 \\
\hline$P I B \_P C$ & $\begin{array}{c}0.61 \\
0.0017 \\
\end{array}$ & $\begin{array}{c}0.78 \\
0.0000 \\
\end{array}$ & $\begin{array}{c}0.73 \\
0.0001 \\
\end{array}$ & $\begin{array}{c}0.81 \\
0.0000 \\
\end{array}$ & $\begin{array}{c}0.86 \\
0.0000 \\
\end{array}$ & $\begin{array}{c}0.90 \\
0.0000 \\
\end{array}$ & $\begin{array}{c}0.89 \\
0.0000 \\
\end{array}$ & $\begin{array}{c}0.88 \\
0.0000 \\
\end{array}$ \\
\hline $\begin{array}{r}\text { Nota: } \mathrm{C} \\
\mathrm{I} \\
\text { uente: Eurosta } \\
\text { nlace https://g } \\
\text { nlace a datos } \mathrm{e}\end{array}$ & $\begin{array}{l}\text { cientes de } \\
\text { es de sig } \\
\text { peración } \\
\text { 1/7d8kX } \\
\text { tp://stats }\end{array}$ & $\begin{array}{l}\text { orelación } \\
\text { icación } \\
\text { stadística: } \\
\text { e indicac } \\
\text { ecd.org/In }\end{array}$ & $\begin{array}{l}\text { General } \\
\text { lor de bie } \\
\text { dex.aspx? }\end{array}$ & $\begin{array}{l}\text { Yovernme } \\
\text { hestar pe } \\
\text { DataSetC }\end{array}$ & $\begin{array}{l}\text { nt expendit } \\
\text { rsonal OCD } \\
\text { ode=BLI. E }\end{array}$ & $\begin{array}{l}\text { ure by fu } \\
\text { E https:// } \\
\text { laboració }\end{array}$ & $\begin{array}{l}\text { ction (C } \\
\text { Iww.oec } \\
\text { propia. }\end{array}$ & $\begin{array}{l}\text { FOG) (gov_10a_exp). } \\
\text { Iregionalwellbeing.org/ }\end{array}$ \\
\hline
\end{tabular}

La estimación de un modelo explicativo de la felicidad en función de la producción per cápita indica que aumentos de 1000 euros en el PIB per cápita conducen a un crecimiento de 0.04 puntos en la felicidad. Por otro lado, cuando aumenta la relación entre el gasto social y el PIB per cápita en un 1 por 100 la felicidad aumenta un 0.05 .

(Estimación 1)

Felicidad y gastos sociales totales per cápita:

$$
\begin{aligned}
& L \hat{S}=5.299+0.09 G S_{P C} \\
& \text { S.E. } \hat{\beta}_{i}: \quad(0.258) \\
& t_{\hat{\beta}_{i e x}}: \text { (20.492) } \\
& \text { pvalor: (0.0000) (0.0001) } \\
& R^{2}: \quad 0.585
\end{aligned}
$$

(Estimación 3)

Felicidad y gasto en prestaciones sociales per cápita:

$$
\begin{array}{ccc}
L \hat{S}= & 5.442+0.17 P S_{P C} \\
S . E . \hat{\beta}_{i}: & (0.260) & (0.00004) \\
t_{\hat{\beta}_{\text {iex }}}: & (20.907) & (4.602) \\
\text { pvalor: } & (0.0000) & (0.0002) \\
R^{2}: & 0.585 &
\end{array}
$$

(Estimación 2)

Felicidad y gasto en salud per cápita:

$$
\begin{array}{rlc}
L \hat{S}= & 5.137+0.63 \mathrm{Sd} \\
\hline \text { S.E. } \hat{\beta}_{i}: & (0.201) & (0.00008) \\
t_{\hat{\beta}_{\text {iex }}}: & (25.479) & (7.556) \\
\text { pvalor: } & (0.0000) & (0.0001) \\
R^{2}: & 0.737 &
\end{array}
$$

(Estimación 4)

Felicidad y gasto en educación per cápita:

$$
\begin{array}{rlr}
L \hat{S}= & 5.444+O . G 1 E D_{P C} \\
\text { S.E. } \hat{\beta}_{i}: & (0.260) & (0.00013) \\
t_{\hat{\beta}_{i e x}}: & (20.964) & (4.609) \\
\text { pvalor: } & (0.0000) & (0.0002) \\
R^{2}: & 0.503 &
\end{array}
$$


(Estimación 5)

Felicidad y PIB per cápita:

$$
\begin{array}{rlr}
L \hat{S}= & 5.096+0.04 P I B_{P C} \\
\text { S.E. } \hat{\beta}_{i}: & (0.4340) & (0.000013) \\
t_{\hat{\beta}_{\text {iex }}}: & (11.743) & (3.370) \\
\text { pvalor: } & (0.0000) & (0.0032) \\
R^{2}: & 0.374 &
\end{array}
$$

(Estimación 6)

Felicidad y proporción de gasto social respecto del PIB:

$L \hat{S}=4.640+0.050$ GS / PIB

S.E. $\hat{\beta}_{i}: \quad(0.426)$

$\boldsymbol{t}_{\hat{\beta}_{\text {iex }}}:$ (10.878) (4.510)

pvalor: $(0.0000) \quad(0.0002)$

$R^{2}: \quad 0.492$

\subsection{Análisis del Estado de Bienestar y la felicidad como factores de la producción per cápita}

El PIB per cápita presenta una distribución desigual, asimétrica positiva ${ }^{8}$ entre los países de la UE cuyos valores oscilan entre los 13580.9 euros de Bulgaria y los 79577.3 de Luxemburgo, siendo el promedio europeo por habitante de 20366.9 euros. Las naciones del Norte y del Centro muestran las mayores cantidades de PIB per cápita, desde los 40340.6 de Irlanda a los 31611.3 euros de Francia, mientras que la mayoría de los países que se incorporaron a la UE a partir del año 2004 observan los valores más pequeños.

\section{MAPA 5. DISTRIBUCIÓN ESPACIAL DEL PIB PER CÁPITA EN LA UE, 2014}

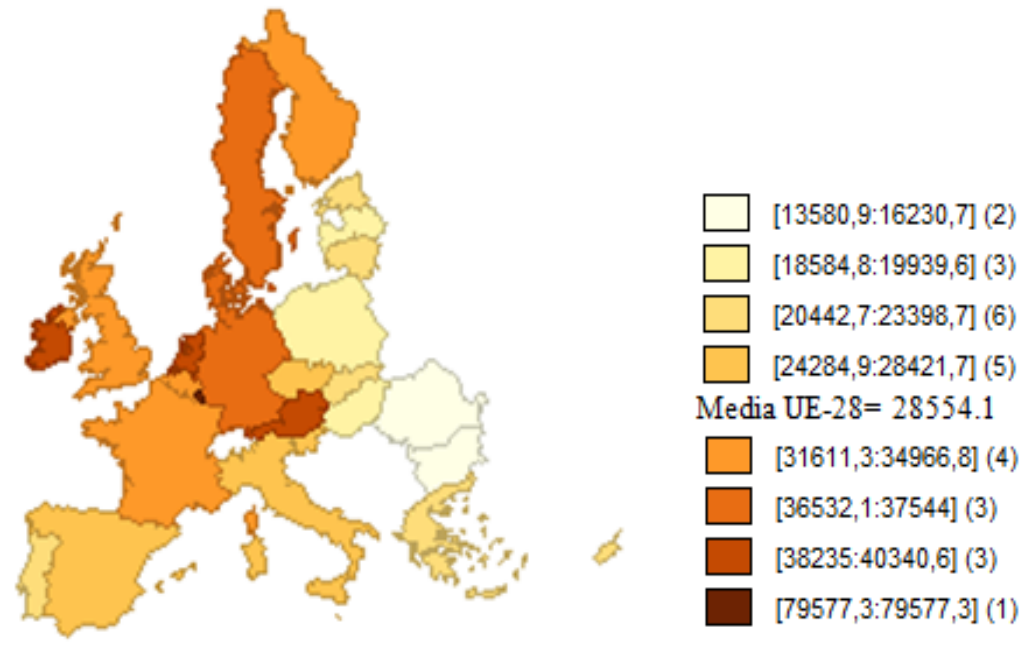

Nota: Los intervalos expresan los límites del PIBpc en cada clase. El número entre paréntesis indica el número de países en cada clase.

Fuente: Eurostat. Operación estadística: General government expenditure by function (COFOG) (gov_10a_exp). Enlace https://goo.gl/7d8kXK. Elaboración propia.

También se ha realizado la estimación de un modelo explicativo del PIB per cápita en función del gasto social y la felicidad. Estas variables presentan correlaciones directas, altamente significativas, con el PIB per cápita de 0.88 y 0.61 , respectivamente. Dada la

\footnotetext{
${ }^{8}$ El coeficiente de asimetría de Fisher toma el valor de 2.53. Consecuentemente, la mayoría de los países toma valores bajos de PIB per cápita y se produce una dispersión debido al elevado valor de Luxemburgo.
} 
diferente escala de la felicidad con el resto de variables, se han transformado los valores del PIB per cápita y del gasto social per cápita a logaritmos naturales.

Los resultados de la estimación ponen de relieve la falta de significación de la variable felicidad para el modelo. Por otro lado, sí resulta significativo el $\operatorname{Ln}\left(G s_{P C}\right)$. Así, cuando el gasto social per cápita aumenta un 1 por 100, el PIB per cápita se incrementa un 0.395 por 100.

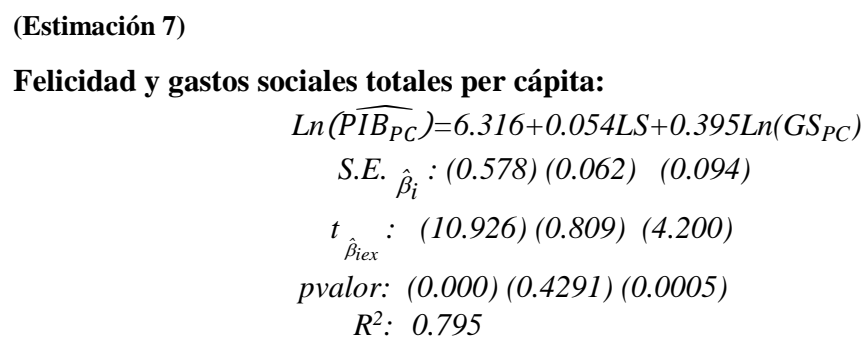

Para finalizar, se ha efectuado un diagrama de dispersión tridimensional con las variables de PIB per cápita, gasto social per cápita y felicidad. Los resultados muestran que a partir de 13000 euros de gasto social per cápita y de 33000 euros de PIB per cápita no existen diferencias significativas en la felicidad subjetiva de la población de los 21 países de la UE estudiados para el año 2014 (gráfico 5).

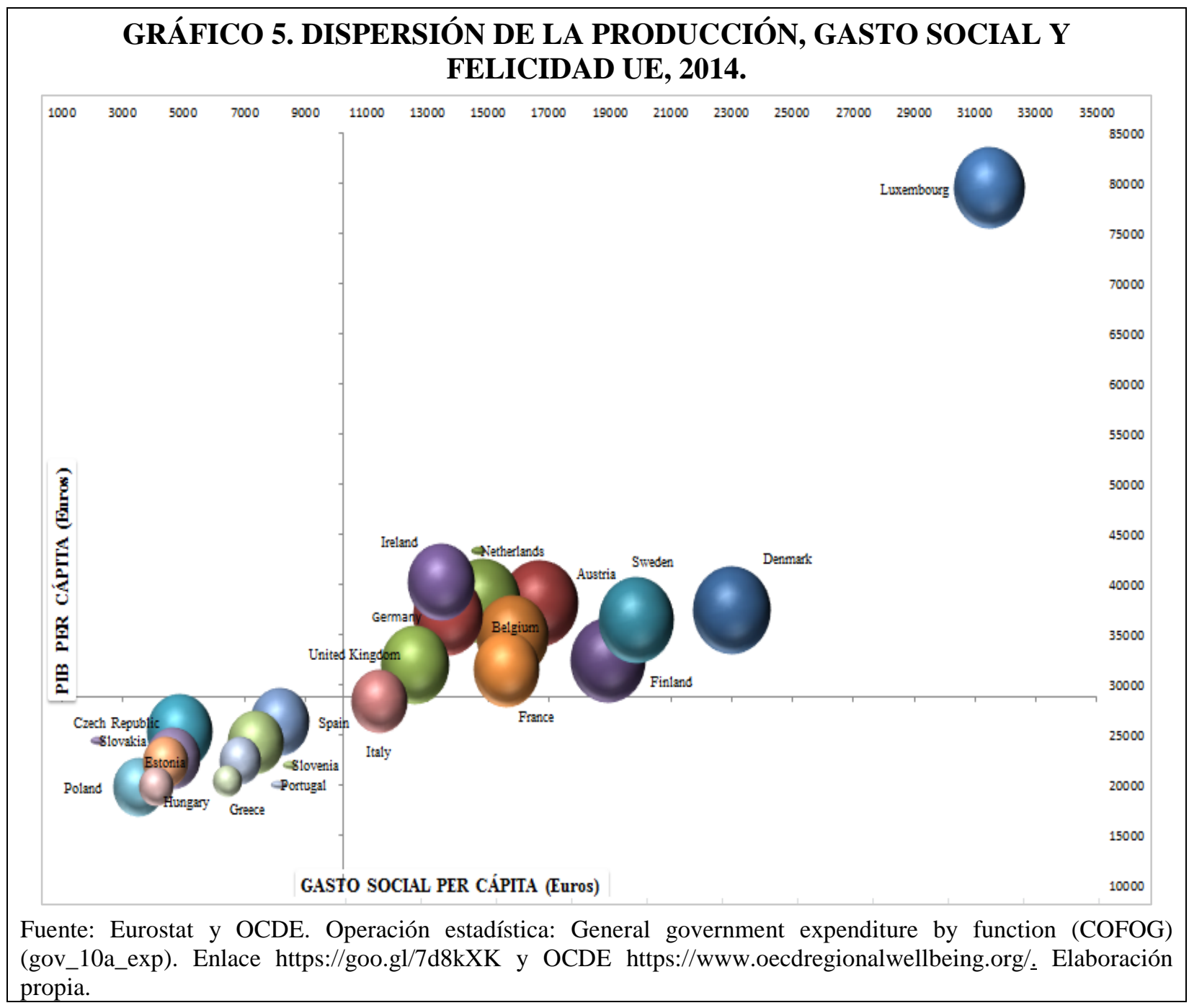




\section{CONCLUSIONES}

En este estudio se han realizado tres análisis: el primero, el gasto social; el segundo, la felicidad; y el tercero la producción per cápita de los países de la UE en el año 2014.

Los resultados del análisis del gasto social han permitido comprobar que existen importantes desigualdades en el Estado de Bienestar de los países de la UE, así como una importante asociación entre los gastos sociales y la estructura de la población dependiente.

Los países que han mostrado un Estado de Bienestar más desarrollado son Dinamarca, Finlandia, Suecia, Alemania e Irlanda. La distribución del gasto social no ha presentado diferencias significativas en estos países, excepto Irlanda. Las prestaciones sociales oscilan entre el 44 por 100 de Dinamarca y el 41 por 100 de Suecia; los gastos en sanidad entre el 16 por 100 de Dinamarca y Alemania y el 14 por 100 de Suecia y Finlandia; los gastos en servicios públicos generales entre el 15 de Suecia y el 13 por 100 de Dinamarca; y los gastos en educación entre el 13 de Dinamarca y el 10 por 100 de Alemania. Por otro lado, Irlanda ha presentado un gasto menor en prestaciones sociales del 35 por 100 debido a la juventud de su población, mayor en sanidad del 20 y en educación del 11 por 100.

En sentido opuesto, los países con Estado de Bienestar menos desarrollado, los que destinan menor presupuesto a gastos sociales, son los países del Este de Europa (Rumanía, Estonia, Bulgaria, Letonia y la República Checa). La composición interna de los gastos sociales de estos países también ha mostrado estructuras diferentes en las prestaciones sociales, que oscilan entre el 33 y 31 por 100. Los gastos en servicios públicos generales, salud y educación, respectivamente, en Rumanía han sido del 13, 11 y del 9 por 100; en Estonia del 10, 14 y 15; en Bulgaria del 15, 13 y 10; en Letonia del 13, 10 y 16; y en la República Checa del 11, 18 y 12 por 100.

El análisis de la felicidad se ha realizado para 21 países de la UE y ha puesto de relieve que los ciudadanos de países con Estado de Bienestar más desarrollado son más felices. Así, los resultados han reflejado que los países más felices son los del Norte y Centro de Europa con niveles superiores a 7 en felicidad, y los menos felices son los países de la Europa Oriental cuyos valores son inferiores a 6. El estudio de la felicidad y los gastos sociales de forma conjunta indica que estas variables están directa y altamente relacionadas, aunque no se ha podido realizar una estimación de la felicidad con el conjunto de gastos sociales debido a la existencia de multicolinealidad.

El estudio individual de cada gasto social con la felicidad ha mostrado que el gasto en salud es la variable que más felicidad aporta (0.63 puntos por un aumento de 1000 euros), seguido de la educación (0.61 puntos por un aumento de 1000 euros) y las prestaciones sociales (0.17 puntos por un aumento de 1000 euros). Por tanto, se puede afirmar que un aumento en el Estado de Bienestar en los países de la UE hace que sus ciudadanos sean más felices. Asimismo, la producción también se encuentra directamente relacionada con la felicidad, aunque en menor medida que el gasto social, un aumento del PIB per cápita de 1000 euros solo incrementa la felicidad 0.04 puntos.

Por último, el análisis de la producción ha mostrado una asimetría positiva en la distribución espacial del PIB per cápita de los países de la UE. Los países del Norte y Centro de Europa presentan mayores valores en el PIB per cápita que el resto de los países. Entre ellos, destaca Luxemburgo con 79577.3 euros y le siguen 10 países cuyos valores oscilan entre los 40340.6 de Irlanda y los 31611.3 euros de Francia mientras que el promedio europeo se sitúa en 20366.9.

Asimismo, la estimación de un modelo log-log explicativo del PIB per cápita en función del gasto social y la felicidad para 21 países de la UE ha puesto de manifiesto que el gasto 
social per cápita es significativo mientras que la felicidad no lo es. Un incremento del gasto social per cápita de un $1 \%$ aumentará el PIB per cápita en un $0.395 \%$. Además, la representación del diagrama de dispersión tridimensional (PIB per cápita, gasto social per cápita y felicidad) ha mostrado que, a partir de cierto nivel de renta y gasto social, la felicidad no presenta variaciones significativas.

Por tanto, con este estudio se ha podido constatar que existen diferencias significativas en el Estado del Bienestar, en la distribución del gasto público y en la producción en los países miembros de la UE. También, se ha confirmado que los ciudadanos con mayor Estado de Bienestar son más felices, que para la productividad per cápita es más significativa el gasto público per cápita que la felicidad y que la renta afecta a la felicidad, pero hasta que esta alcanza cierto grado, a partir de ese nivel, un aumento de renta no mejora la felicidad.

La realización de este artículo ha planteado dos nuevas cuestiones a desarrollar en próximas investigaciones. La primera, si a escala mundial el nivel de renta influye en el grado de felicidad y si existen diferencias significativas según los continentes. La segunda, si el gasto social per cápita tienen el mismo efecto sobre la productividad y la felicidad a nivel nacional (España) y en las comunidades autónomas.

\section{BIBLIOGRAFÍA}

Angulo, G. M., Quejada, R. y Yánez, M. (2012): “Educación, mercado de trabajo y satisfacción laboral: el problema de las teorías del capital humano y señalización de mercado", Revista de la educación superior, n 41 (163), pp. 51-66.

Bailey R., Hillman, C., Arent, S. y Petitpas, A. (2013): "Physical activity: an underestimated investment in human capital”, Journal of physical activity and health, $\mathrm{n}^{\circ} 10$ (3), pp. 289-308.

Bergqvist, K., Yngwe, M.A., y Olle L. (2013): "Understanding the role of welfare state characteristics for health and inequalities-an analytical review”, BMC Public Health, $n^{\circ} 13$, pp. 1-20.

Boisier, S. (2010): "Descodificando el desarrollo del siglo XXI: subjetividad, complejidad, sinapsis, sinergia, recursividad, liderazgo, y anclaje territorial”, Semestre Económico, $\mathrm{n}^{0} 13$ (27), pp. 11-37.

Bowles, S. y Gintis, H. (2014): "El problema de la teoría del capital humano: una crítica marxista”, Revista de economía crítica, n 18 , pp. 220-228.

Cruz, J., y Torres, T. (2016): “¿De qué depende la satisfacción subjetiva de los colombianos?”, Cuadernos de Economía, no 25(45), pp. 131-284.

Csikszentmihalyi, M. (2008): Fluir: una psicología de la felicidad, Barcelona, Kairós,

Díaz, R., Portela, M. y Neira, M. (2011): "Bienestar y felicidad: relación con la renta y el capital social en países europeos”, Revista galega de economía, n 20, pp.1-29.

Dutschke, G. (2013): "Factores condicionantes de felicidad organizacional. Estudio exploratorio de la realidad en Portugal”, Revista de Estudios Empresariales. Segunda Época, $\mathrm{n}^{\circ}$ 1, pp. 21-43.

Easterlin, R. A. (2013): “Happiness, Growth, and Public Policy”, Economic Inquiry, no 51(1), pp. 1-28.

Esping, G. (2016): The three worlds of welfare capitalism, Cambrigde, Polity Press, 1990. Eurostat, Statistical approaches to the measurement of skills, Statistical Working Papers. Luxembourg, Publications Office of the European Union, 2016. 
Fernández, T. (2012): "El estado de bienestar frente a la crisis política, económica y social”, Portularia: Revista de Trabajo Social, n 12 , pp. 3-12.

Ferragutti, G. (2015): “Gubernamentalidad y Capital Humano. Hacia un esbozo de las condiciones de emergencia de los discursos sobre sociedad de la información, educación y nuevas tecnologías. De Prácticas y Discursos”, Cuadernos de Ciencias Sociales, $\mathrm{n}^{\circ} 1(1)$, pp. 1-16.

Fresno J.M., Renes, V., y Tsolakis, A. (2012): “Estrategia Europea 2020 e inclusión social: distanciamiento creciente entre objetivos, políticas e instrumentos”, Revista de servicios sociales, $\mathrm{n}^{\circ} 51$, pp. 27-47.

González, A. M. (2004): “Cultura y felicidad en Kant”, Teorema: Revista internacional de filosofía”, nº 1/3, pp.215-232.

González, R.M. (2011): "El Pacto de Estabilidad y Crecimiento ante la crisis. Determinación y seguimiento del déficit público de los Estados miembros de la Unión Europea”, Revista española de control externo, 13 (39), pp. 65-104.

Helliwell, J.F., y Putnam, R.D. (2004): “The social context of well-being”, Philosophical transactions-royal society of London series B biological sciences, $\mathrm{n}^{\circ} 359$, pp.14351446.

Hernández, J.L. (2010): "Inversión pública y crecimiento económico: Hacia una nueva perspectiva de la función del gobierno”, Economía: teoría y práctica, nº 33, pp. 59-95.

Navarro, V. (2004): El Estado de bienestar en España, Ed. Tecnos, Madrid.

Navarro, V. (2012): "El error de las políticas de austeridad, recortes incluidos, en la sanidad pública”, Gaceta Sanitaria, 26(2), pp. 174-175.

Navarro, V. (2015): Bienestar insuficiente, democracia incompleta, Ed. Anagrama, Barcelona.

OECD, (2016): ¿Cómo va la vida? 2015: Medición del bienestar, Paris, OECD, 2015 DOI: http://dx.doi.org/10.1787/9789264240735-es

OECD (2001): The well-being of nations. The role of human and social capital. Education and skills, Ed. OECD, Paris.

Ott, J.C. (2016): "Perceptions of the Nature of Happiness: Cultural, but Related to the Dynamics of the Human Mind and the Gratification of General Needs", Journal of Happiness Studies, pp.1-7. Doi: 10.1007/s10902-016-9720-6.

Pacek, A. y Radcliff, B. (2008): “Assessing the welfare state: The politics of happiness”, Perspectives on Politics, n 6(02), pp. 267-277.

Pozos J.L., Rivera, S. Reidl, L.M., Vargas, B.I. y López, M.S. (2013): "Felicidad general y felicidad en la pareja: diferencias por sexo y estado civil”, Enseñanza e Investigación en Psicología, $\mathrm{n}^{\circ}$ 18(1), pp. 69-84.

Rodríguez, C. (2014): “La contra-reforma educativa en España: políticas educativas y neoliberales y nuevos modelos de gestión”, Revista interuniversitaria de formación del profesorado, $\mathrm{n}^{\circ}$ 81, pp. 15-30.

Rodríguez, G. (2004): El Estado de Bienestar en España: debates, desarrollo y retos, Ed. Fundamentos, Madrid.

Salinas, M.M. y Salinas J. (2008): “Educación y bienestar subjetivo: Una aproximación desde la Economía de la Felicidad”, Presupuesto y Gasto Público, nº 53, pp. 107-118.

Savater, F. (2012): El contenido de la felicidad, Ed. Aguilar, Madrid. 
Villalobos, G., y Pedroza, R. (2009): "Perspectiva de la teoría del capital humano acerca de la relación entre educación y desarrollo económico", Tiempo de educar, n 10(20), pp. 273-306.

Warr, P. (2011): Work, happiness, and unhappiness, Psychology Press, Abingdon, Oxon.

Warr, P. (2013): "Fuentes de felicidad e infelicidad en el trabajo: una perspectiva combinada”, Revista de Psicología del Trabajo y de las Organizaciones, n 29(3), pp. 99-106.

World Health Organization (WHO) (2014): Report on the global tobacco epidemic, 2013: enforcing bans on tobacco advertising, promotion and sponsorship, Ed. World Health Organization, Geneva. 


\section{Clasificación COFOG de los gastos gubernamentales de tipo social}

\begin{tabular}{|c|c|}
\hline $\begin{array}{c}\text { Tipos de Gasto según } \\
\text { Objetivos generales del gobierno } \\
\text { (división) }\end{array}$ & \\
\hline 01. Servicios públicos generales & $\begin{array}{l}\text { 01.1. Órganos ejecutivos y legislativos, asuntos financieros fiscales, asuntos externos } \\
\text { 01.2. Ayuda económica extranjera } \\
\text { 01.3. Servicios generales } \\
\text { 01.4. Investigación básica } \\
\text { 01.5. I+D en relación con los servicios públicos generales } \\
\text { 01.6. Servicios públicos generales } \\
\text { 01.7. Transacciones de la deuda pública } \\
\text { 01.8. Transferencias de carácter general entre distintos niveles de gobierno }\end{array}$ \\
\hline 06. Vivienda y servicios comunitarios & $\begin{array}{l}\text { 06.1. Desarrollo de la comunidad } \\
\text { 06.2. Desarrollo de la vivienda } \\
\text { 06.3. Abastecimiento de agua } \\
\text { 06.4. Alumbrado público } \\
\text { 06.5. I+D en servicios a la comunidad y la vivienda } \\
\text { 06.6. Servicios de la comunidad y la vivienda }\end{array}$ \\
\hline 07. Salud & $\begin{array}{l}\text { 07.1. Equipo, instrumental y productos médicos } \\
\text { 07.2. Servicios a pacientes externos } \\
\text { 07.3. Servicios hospitalarios } \\
\text { 07.4. Servicios de salud pública } \\
\text { 07.5. I+D en salud } \\
\text { 07.6. Salud }\end{array}$ \\
\hline 08. Ocio, cultura y religión & $\begin{array}{l}\text { 08.1. Servicios deportivos y de ocio } \\
\text { 08.2. Servicios culturales } \\
\text { 08.3. Servicios de edición y radio fusión } \\
\text { 08.4. Servicios religiosos y otros servicios comunitarios } \\
\text { 08.5. I+D en ocio, cultura y religión } \\
\text { 08.6. Ocio, cultura y religión }\end{array}$ \\
\hline $\begin{array}{l}\text { 09. Educación } \\
\text { (Servicios públicos) }\end{array}$ & $\begin{array}{l}\text { 09.1. Educación prescolar y primaria } \\
\text { 09.2. Educación secundaria } \\
\text { 09.3. Educación postsecundaria, no terciaria } \\
\text { 09.4. Educación de tercer ciclo } \\
\text { 09.5. Educación no reglada por niveles } \\
\text { 09.6. Servicios complementarios a la educación } \\
\text { 09.7. I+D en educación } \\
\text { 09.8. Educación }\end{array}$ \\
\hline $\begin{array}{l}\text { 10. Protección social } \\
\text { (Transferencias sociales) }\end{array}$ & $\begin{array}{l}\text { 10.1 Pensiones por enfermedad y discapacidad } \\
\text { 10.2 Pensiones por vejez } \\
\text { 10.3 Supervivientes } \\
\text { 10.4 Ayudas a la familia y los niños } \\
\text { 10.5 Prestaciones por desempleo } \\
\text { 10.6 Ayudas a la vivienda } \\
\text { 10.7 Exclusión social. } \\
\text { 10.8 I+D en protección social } \\
\text { 10.9 Protección social }\end{array}$ \\
\hline
\end{tabular}

Fuente: Eurostat. Elaboración propia. 